\title{
ROBO-ADVISORS AS AUTOMATED PERSONAL FINANCIAL PLANNERS - SWOT ANALYSIS ${ }^{1}$
}

\author{
Krzysztof Waliszewski \\ Poznań University of Economics and Business, Institute of Finance, \\ Department of Money and Banking \\ ORCID: https://orcid.org/0000-0003-4239-5875 \\ Marta Zięba-Szklarska \\ Europejska Federacja Doradców Finansowych, EFFP Polska
}

\begin{abstract}
Automatic financial consulting (robo-advice) is a financial innovation in the area of personal financial planning, and in particular investment consulting classified as fin-tech (financial technology). The main disadvantage of traditional investment advice is limited availability due to the required amount of assets and high management costs. These disadvantages are answered by robo-advice, using artificial intelligence and algorithms without the participation of a physical adviser, thereby reducing or abolishing minimal assets and reducing costs [Kocianski 2016]. The purpose of the article is to analyze strengths and weaknesses as well as opportunities and threats of robo-advisors, especially when compared to traditional financial advisors. This paper is an analysis of a history, regulations, application, functionality and development of Robo-Advice. The concept of Robo-Advice was critically analysed, with presentation of current strength and weaknesses, as well as opportunities and threats. We aimed showing that Robo-Advice should be innovative, feature a new approach, and should transform the current financial consulting. There are still, however, many opportunities and challenges in this field, which await discovering. The article uses the SWOT analysis method, analysis of the literature and reports. As indicated by the analysis, robo-advisors are not a threat to traditional financial advisors, but their complement, which makes the hybrid model connecting a physical advisor assisted by technological solutions (robo-advisors) most likely. This thesis is also confirmed by the small scale of roboadvisors' activity compared to traditional advisors measured by the market penetration rate (in 2023 about $2 \%$ assets under management).
\end{abstract}

Key words: digital financial planning, personal financial management, automated financial advisors, fin-tech regulation.

JEL Class: D14, O30.

1 The article is written within „The project financed within the Regional Initiative for Excellence programme of the Minister of Science and Higher Education of Poland, years 2019 -2022, grant no. 004/RID/2018/19, financing 3000000 PLN". 


\section{INTRODUCTION}

The purpose of the article is to analyze strengths and weaknesses as well as opportunities and threats of robo-advisors, especially when compared to traditional financial advisors. In the article, apart from the review analysis of available literature on the subject, the SWOT analysis method known in management sciences, which indi-cates the opportunities and threats arising from robo-advice services from the environment, as well as strengths and weaknesses arising from within the industry. Without professional personal financial planners management of assets and taking financial risks is a difficult task, both for majority of households, as well as individuals. Financial Consulting is a series of household financial areas which should be addressed when it comes to such a consulting. Investments are just one of such financial consulting areas. A global aspect of personal financial planning should not be disregarded, and it features: savings, assurances, investments, movable assets, immovables, pension, health costs, inheritance succession, etc. Due to the possibility of delivering the right market tool, the current technology and Fin-Tech solutions concentrate mainly on banking services and investments. The remaining aspects of individual financial planning are still too difficult for Robo-Advice operators. But this is merely a matter of time. It must be noted that financial consulting - as opposed to investment, pension, assurance, inheritance, real estate, etc. consulting - is a complex/inter-dependent approach to managing finances of a household, resulting in preparation of long-term financial plan, defining, among others, the parameters of financial products and instruments (for purchase), which would guarantee fulfilment of personal and financial goals. For there are not too many solutions for financial planning and financial consulting in their correct and full scope, we will focus on financial consulting in the sector of banking and investment services, that are usually and currently associated with Robo-Advice operators, bearing in mind that it is just a slice of personal consulting in the field of personal finances. If we take a closer look at the digital financial consulting services (banking and investment services) in various countries, we will notice their growing popularity in private detail banking. These tools support users in:

- taking financial decisions,

- defining products portfolio,

- monitoring incomes and expenditures,

- purchasing banking and investment instruments,

- restoring financial balance and cash flow.

Thus, is it already a revolution or still an evolution in the Fin-Tech area? It is still more of an evolution, as it pertains to a narrow scope of consulting. Though looking at this in a long-term perspective, it may be assumed that artificial intelligence (AI) and machine learning will take control over subsequent areas, supporting both specialist and professionals in their work on financial plans. 
The recent research results suggest that in long-term perspective they might complement the financial consulting provided by humans (financial advisers). Robo-Advice features a great potential for shaping the future of personal financial planning/financial consulting, even though there is still much to do since international research indicates that Robo-Advice services here differ in terms of their level of development, and this is rooted in socio-economic factors [Waliszewski, Warchlewska 2020].

\section{ROBO-ADVICE - NEW PLATFORM FOR INVESTING}

The review of Robo-Advice definitions has been widely presented in the literature [Waliszewski 2020]. LIMRA ${ }^{2}$ defines Robo-Advice as a service of online portfolio management (full and precise definitions are included in this paper), which provides for automated, algorithm-based consulting advices. Many, if not all Robo-Advice platforms' algorithms are based on a modern portfolio theory. There is a minimum interaction with human, and the exchange-traded funds (ETF) are used for allocation of investments based on investor's targets and risk tolerance. Currently, Robo-Advice platforms do not provide solutions for more complex financial needs, such as insurances or pensions, immovables planning, etc., which constitute all other aspects of personal financial planning handled by Financial Advisers/Financial Planners. Additionally, LIMRA conducted a questionnaire on the team of their financial specialists, brokers and advisers, and concluded that seven out of 10 individuals dealing in insurances (independent insurance agents) did not know the capabilities of Robo-Advice. On the other hand, independent investment advisers were more competent with regard to Robo-Advice, and only three out of 10 advisers claimed not to have any knowledge about them. The more disturbing may be the fact that approximately half of participants in that research considers Robo-Advice platforms to have influence on financial services branch. Even those, who agree with that, are short-sighted. Within the next 10 years, we may witness Robo-Advice platforms and systems having more complex (Big Data) picture of clients' needs and offering not only a more refined investment options, but also life insurances and connected products, and in time the remaining fields of personal financial planning. No wonder that insurance providers create products specifically for Robo-Advice, and use this opportunity as a means of accessing other channels of distribution and new clients. According to Jung, Dorner, Glaser and Morana [2018] digitalization in financial advisory services it took place in two phases - in the first phase there was a transition from traditional financial advisors to online platforms, in the second phase there was a transition to Robo Advisers (Scheme 1).

${ }^{2}$ LIMRA Inc., an association of life insurance and financial services companies, performs research and other. 


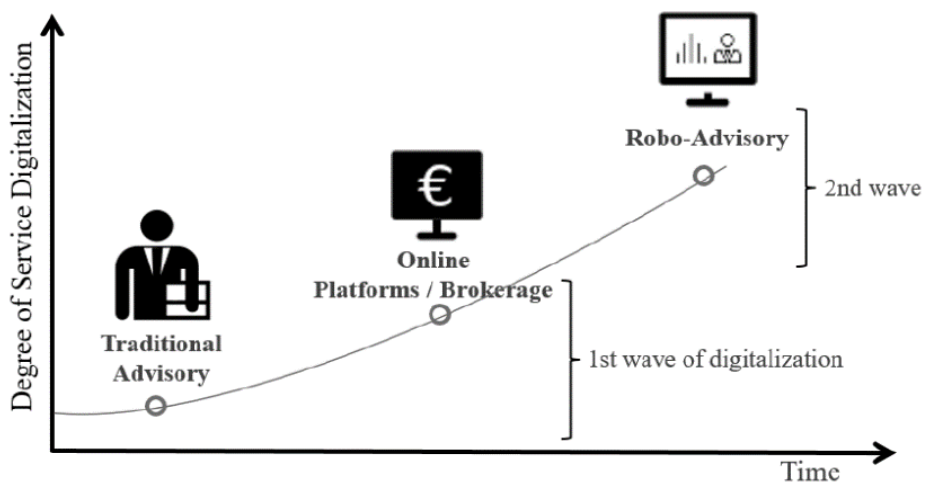

Scheme 1. Waves of digitalization in financial services from traditional to Robo-Advice

Source: Jung et al. 2018.

The financial sector operates in good macro-economic surrounding, but it faces new, difficult conditions. Technological innovations and pressure of profitability compel the market to undertake subsequent automation of financial service processes. The ending of major aspects of financial market regulations marks the opening of space for further development of financial institutions.

The digital transformation is a fact, not just merely steady prognoses for the years to come. The demand for and usage of digital services in almost all aspects of consumers' lives is growing constantly. Online accounts, online payments, internet shopping, selection of products are all a standard, not an exception. In the scope of advancing digitalization, Robo-Advice entered the market, providing fully automated investment solutions for a wide group of potential clients (both, for the wealthy ones, with enormous amounts of money, and for the small investors, with highly limited budgets). The systems create portfolios for their clients, make investments subject to individually customised risk, manage such portfolios while addressing market changes, changes in features of assets and a benchmark in the form of data collected about other investors. It may be potentially assumed that Robo-Advice will limit usage of human-delivered services, as it decreases the investment management costs (even down to $0 \%$, as it was analysed in the U.S., Schapiro [2017]). This is also evidenced by money invested by Venture Capital in Fin-Tech solutions, estimated to amount to several hundred million dollars [Wong 2015], or prognoses that in 2020 Robo-Advice will conquer over $10 \%$ of the entire assets management [Kocianski 2016]. It is necessary to consider the fact that digitalisation, being the most recent Robo-Advice building trend, will revolutionise the market of financial services. Taking this into consideration, it is a must to consider the need for analysing character of these changes, evaluate the opportunities and threats for this process and assess the potential of this market. 


\section{Financial Consulting in the Area of Banking and Investment Products}

The branch of financial services faces serious changes in its traditional form of consulting and personal financial planning operations.

The main goal of the financial consulting (for the purpose of this paper only one area of individual financial planning is covered, i.e. the field of investments) is the assistance to physical persons or institutions in making the right investments, fulfilling their individual investment goals and considering long-term or short-term investment perspectives. This definition comes hand in hand with the definition of investment consulting. As stipulated in the EU MiFID Directive, the investment consulting means 'providing personal recommendations to clients, when requested or through the initiative of an investment company, with regard to one or more transactions connected with financial instruments' [Cocca 2016].

The MiFID Directive is an EU regulation, supported by ESMA guidelines, and aiming at an improvement of competitiveness of EU financial markets through creation of common market of services and investment activities, and securing the investors with high level of harmonized protection with relation to financial instruments [European Securities and Markets Authority, 2007].

Until the present day, the possibility of using investment consulting or investment advices was available mainly for the wealthy investors, for their individual considerations, generally due to high fees collected for such services. However, this market has been opened lately also to low-budget investors. In the last decades, the market underwent changes. Personal financial consulting and assets management, which had constituted exclusive and very expensive services dedicated to very wealthy individuals, started to be, in time, more and more available and ubiquitous. The most important change took place in the 1970s, when the investment advisers opened to the American middle class. Another important date falls to the 1990s, when the economy stood on the verge of crucial changes in communication and availability due to introduction of Internet. With Internet, the online trade was theoretically available for even a broader group of investors. In subsequent years, the IT technology was developing increasingly faster. The highly developed communication via computers, smartphones, tablets, etc., as well as the decreasing asymmetry of information spurred by the easier and faster access to information, greatly diminished the transaction costs. The algorithmic trade (so-called AlgoTrading) emerged, which represents the fully automated investment instruments and provides for the new possibilities for potential investors. Currently, a radical change in behaviour of individuals was caused by technological changes, but also by unprecedented knowledge of social media and digital tools [Sironi 2016]. All of this was just an introduction to subsequent changes and emergence of new subjects and 
systems, which will shortly revolutionise the market, by simplifying operation, decreasing charges and contextually generating new investment strategies for potential investors, the so-called Robo-Advice [Nicoletti 2017].

\section{Robo-Advice and Traditional (Human) Consulting}

Interesting data on Robo-Advice is provided by a study Wells Fargo/Gallup Investor and Retirement Optimism Index survey 2016 from the most-developed US market that compares human advisor and Robo Advisor (Chart 1).

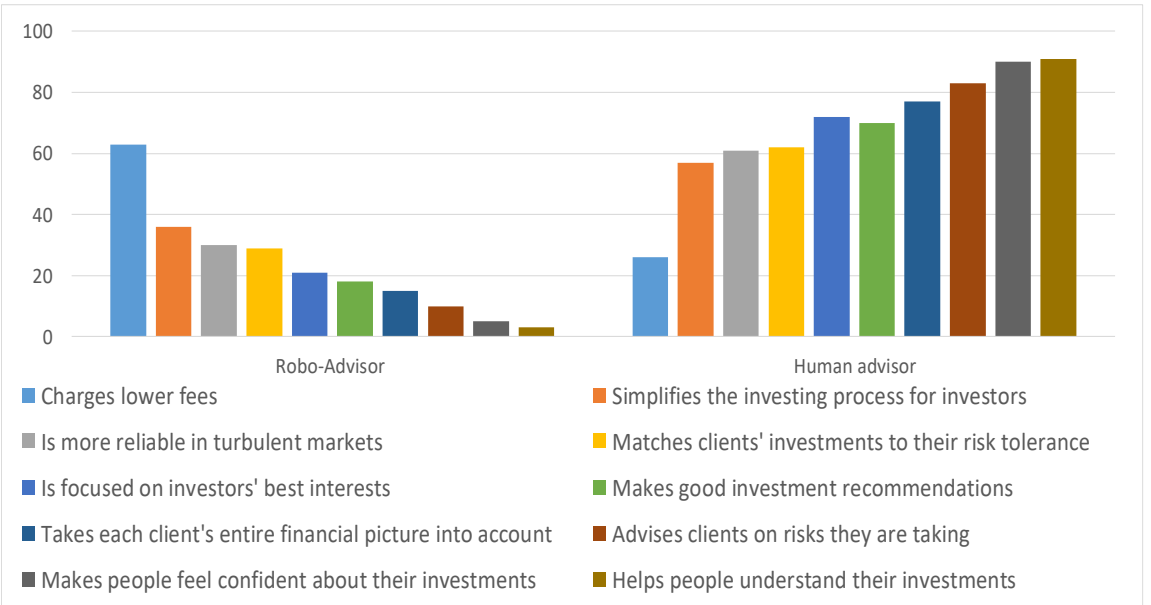

Based on investors who have heard about Robo-Advisers

Chart 1. U.S. Investors' Perceptions of Human vs. Robo-Advice

Source: Saad 2016, https://news.gallup.com/poll/193997/robo-advice-novelty-investors.aspx [access 15.02.2020].

Human advisers lead on almost all qualities measured in the survey. However, on the continuum of things investors think humans do better, Robo-Advice is perceived relatively well on a few process-oriented items. Investors choose robo-over human advisers for charging lower fees. And at least one in four investors associate Robo-Advice with simplifying the investing process (36\%), being more reliable in turbulent markets (30\%) and matching clients' investments to their risk tolerance (29\%). These results support the hypothesis that it should be assumed that the model of cooperation between human advisors and Robo-Advisors is currently the most realistic.

Robo-Advice are digital platforms, which cover interactive and smart components assisting the users, utilising IT technology for guiding clients (based 
on machine learning solutions) through the automatic process of consulting in the field of banking and investment products. The Robo-Advice services differ from the traditional consulting services. They pertain to quantitative evaluation of a client and management of client portfolio. The target group is constituted here by households and individual clients. There is no control process nor client selection, and the Internet platform enables simple registration process and automatic client profiling via:

- self-reporting to quantify a person's profile;

- preparation of a questionnaire for measurement of an attitude towards risk;

- defining preferences, goals and particular interests stemming from the self-assessment questionnaires.

The entire investment process carried out through Robo-Advice platforms is automated and does not require human activity to profile clients, nor to manage the portfolio. The characteristic features are:

- allocation of assets is based on quantitative optimization;

- portfolio balancing: active (interactions with a client) / passive (only quantitative);

- evaluation of portfolio strategy: dynamic (client-based adjustments) / static (defined after the initial period);

- passive investment products;

- no actively managed financial products to reduce costs;

- instruments with transparent cost structure;

- pool of choice - exchange-traded funds (ETF), exchange-traded commodities (ETC).

The potential and perspectives for development of Robo-Advice are thus enormous, as for example [Anderson 2017]:

1. The consequence of a fully automated client and investment process profiling are a structure of relatively low charges and minimum investment.

2. The Generation Y/Millennials is the core target group for Robo-Advice.

3. The estimated threshold of profitability is much lower than the potential market, thus this is attractive for companies entering the market.

4. Summing up, the main reasons, why robot advisers may interfere with the traditional consulting business are: low costs, ease of access and attractiveness for new clients, such as the Generation Y/Millennials and technology-oriented investors.

In order to reach a considerable number of investors, such Robo-Advice platforms, like Betterment or Scalable Capital, had started with unmanaged market of low-budget investors. Then, they moved on to reach for wealthy investors, possessing high value net amounts, 'stealing' the clients from the traditional companies [Sironi 2016]. 
As of now, the traditional assets management and personal financial planning increasingly often integrate Robo-Advice solutions with its business and classic consulting models. The most popular examples of such a hybrid consulting structure are Vanguard Personal Advisor Services and Schwab Intelligent Portfolios.

The hybrid consulting services combine Robo-Advice with classic services and skilfully use the available tools and systems for the development of the range of their services.

Owing to such an approach, the time-consuming and automation-capable actions are taken over by a machine. Among others, these are:

1. initiation of financial consulting;

2. client profiling, identification of investment needs and goals;

3. client evaluation, risk and client's investment profile measurements based on profiling and automatic/cognitive self-assessment (age, risk tolerance, investment amount).

When a potential investor registers at the website and confirms the will to invest, the first step in interaction is the evaluation of certain factors, e.g.: individual aversion to risk and investment perspective, which are then required for constructing the recommended portfolio. This procedure requires the investor to answer the prepared questionnaire, containing questions differing depending on the company and country.

Employment of a questionnaire, without preliminary consultancy or meeting with a financial adviser in person, is a big step forward in comparison to traditional personal financial planning and assets management services. Through using the questionnaire, the investor is rewarded with a feeling of making a logical choice of a portfolio, without recommendations of a third party and more based on own opinions [Sironi 2016]. The procedure following the filling-in of a questionnaire and delivering it was executed fully automatically.

Then, an advisor, a real-life physical person, begins to work on a well-organised data, providing a complex service, that covers:

1. Definition of investment strategy.

2. Introduction of a defined strategy (possible only after preparation of a full personal financial plan).

3. Generation of long-term models portfolio (visualisation of investment proposals).

4. Money management (trainee, external, hybrid).

5. Portfolio monitoring and balancing, return to optimal portfolio model.

6. Communication (push/pull, event-driven, narrative, digital, etc.), client retention and information. 
These enumerated functions may also be in vast majority handled by automated consulting platforms. In such a case, the role of a human in such a process decreases to absolute minimum.

\section{Robo-Advice Functionality}

Robo-Advice system utilize various approaches to the selection of the right assets classes (e.g. shares, bonds, currencies, commodities), pursuant to a profile of each single investor. The selection of assets class is based on answers given in the questionnaire and may include individual risk preferences, types of goals, tax conditions, etc. [Arnott et al. 2000]. For example, a goal may be to aggregate pension savings, thus it implies a longer investment perspective. Another example is a person very reluctant to risk, who probably prefers bonds with high credit ratings more than stocks, as the risk of insolubility of such bonds is very low. In the case of individuals more risk-prone, the stocks may be included in a portfolio to a greater extent due to high capital rise, inflation protection and tax effectiveness [Lam 2016]. The challenge for automation is to correctly identify such investor's preferences and goals on the basis of digital interaction with a client, who may not be able to precisely define own preferences or may be biased. In such a case, a robot may not always perform well, as it may disregard important aspects, which do not influence the client directly, as well as not to address other questions connected with the total personal finances (assets, financial liquidity, pension, health care, immovables, assurances, taxes, inheritance succession, etc.). Thus, as of now, Robo-Advice proves best in servicing banking and insurance products, as well as investments that stem directly from investor's needs.

Another aspect of automation of investment processes is risk tolerance. Each Robo-Advice platform features many funds for each class of assets and makes it possible to move assets between them, to reach more or less advanced goals. After successful determination, which classes of assets should be considered, proper portfolio weights should be selected for different assets classes, as they indicate how much of a certain assets component in comparison to others should be considered in a portfolio. The most meaningful and modern approach to estimation of optimum and, at the same time, effective portfolio weights is defined in the modern theory of portfolio (or analysis of variance average) [Markowitz 1952]. Basically, the modern theory of portfolio features mathematical frames that include a set of risky assets and calculating portfolios, for which an expected return is maximised for a given risk level of a portfolio [Lam 2016]. The majority of Robo-Advice platforms utilizes the modern portfolio theory or its modifications to define portfolio weights for given assets classes. The first stage covers the 
estimation of return and changeability of various assets classes, which usually is effected through analysis of historical returns and changeability of assets. When the assumptions of capital market are defined, an optimization of variance average is conducted. The optimization is based on a risk profile, preliminary identified on the basis of an investor's questionnaire, with consideration for correlation between various assets classes. At the end, such an approach leads to a successful estimation of portfolio weights [Lam 2016].

After making an investment, an 'algorithmic balancing' will provide for stability of portfolio weights, and thus the stability of risk level, through moving investments between assets classes in order to return to the set, long-term risk balance, when the portfolio weights are changing. This may stem from high and low performance of individual assets or external factors, e.g. dropping markets. Thanks to such an approach, each investor remains at a given risk level and does not have to remunerate for this. Additionally, robots perfectly handle changes of risk preferences and introduce the right corrections to the managed portfolio. What is important, the systems monitor the investment process automatically and are available $24 / 7$.

To sum up, the key benefits of Robo-Advice's investment process are: personalised approach to using questionnaires, recommendation of a portfolio based on scientific data, simple usage, automatic balancing and constant monitoring of investments.

\section{METHODOLOGY}

In the article, apart from the review analysis of available literature on the subject, the SWOT analysis method known in management sciences, which indicates the opportunities and threats arising from Robo-Advice services from the environment, as well as strengths and weaknesses arising from within the industry. Due to the fact that Robo-Advice is included in financial innovations, as well as the alternative financial services market, which is less regulated than the main market, regulatory aspects are an important element of the analysis.

\section{RESULTS OF SWOT ANALYSIS OF ROBO-ADVICE}

When attempting to discuss the below points and structure them properly, it is necessary to realize the essence of personal financial planning and address the fact that today only one of its areas is addressed - the investments. There must, however, be a square one. Subsequently automated areas should consider the existing accomplishments of science and practice. 
The conclusions drawn on the basis of utilising system solutions:

- Lower charges and minimum investment.

- Many users of a single platform and investment benchmark.

- Recovery of tax losses.

- Investment experience (machine learning).

- Creation of a portfolio with algorithms and automatic balancing.

- Less emotional investment decision making.

- Ubiquity of digital services.

- Possibility of standardization and integration of investments based on targets.

- Complementary and good tool for financial advisers.

- Investment costs are not minimised.

- Conflict of interests.

- Poor evaluation of risk tolerance and lack of personalisation.

- No direct contact.

- Unfulfilled fiduciary duty.

- Competitive environment.

- No users' acceptance.

- Possible threat posed by control authorities.

- Bear market and crisis.

\section{Strengths of Robo-Advice}

Two key benefits of Robo-Advice are: relatively low structure of charges and low or lack minimum investment requirements.

The investment platforms allow for registration with even zero capital and invest with 0.01 value of a currency. The charges are much lower, as the platforms invest mainly in the exchange-traded funds. The majority of charges feature also regressive structure and counter-correlated with the invested amount (this means that greater investments lead to lower percentage charges, and vice versa).

The structure of low charges and low minimum investments of Robo-Advice is a real break-through in financial consulting on banking and investment products, as the traditional advisers charge fees for this range of services in the amount of $1-3 \%$ of the portfolio value. More than that, Robo-Advice platforms win access to new, potential low-budget investors, who were not considered as target clients for traditional consulting companies.

Another vital and beneficial aspect of the above is the possibility of tax losses recovery. Thanks to such an approach, the investors from the U.S. may earn with two methods. First, the tax savings may be reinvested to aggregate additional tax savings. Second, due to different tax rates for long-term and short-terms capital 
profits, arbitrage of tax rates may be conducted. Recovery of tax losses is a value added for long-term investors in comparison to individual investments. However, the usability of recovery of tax losses is limited to countries employing various tax rates for short- and long-term capital profits.

The investment experience and benchmark - Robo-Advice platforms feature many users. Their investor bases grow very rapidly, and this enables them to collect data on general and individual level. As a consequence, a well-tuned machine learns through filling its database with subsequent cases and investments. Moreover, additional data and analyses are collected externally. The investor, no matter how experienced, having access to the correctly constructed platform and fully digitalised Robo-Advice systems, and with the use of contemporary technology tools, like smartphones, computers, etc., possesses unlimited investment opportunities. Additionally, transparent interfaces allow to understand well the offer and maintain trust in one's causative power, as the questionnaires and data presentation provide for the possibility of viewing model portfolio as a logical selection according to own opinions and not external indications.

Portfolio optimization in the majority of available Robo-Advice systems is based on a modern theory of portfolio. Advanced risk management is enabled by the defined algorithms and automatic balancing. The results effected by such a use of systems is clearly visible when the efficiency of Robo-Advice platforms is scrutinised. A research conducted by Reher \& Sun [2016] shows that the platforms outmatch both portfolios of self-managed funds and mutual investment funds (risk adjusted). This advocates for modern theory of portfolio, as well as for passive investment strategy of Robo-Advice platforms. The same research evidences that investors seem not to switch to Robo-Advice, even if the platforms generate higher profits. What is more - although the contemporary theory of portfolio is very modern - there are still difficulties in evaluation of short-term strategies, which indicates that Robo-Advice are more valuable in a long-term perspective than in a short-term perspective [Nicoletti 2017].

Lately, a less emotional decision making has been an important strength of Robo-Advice. An average investor may build a portfolio, but when a market turns down on the investor, whatever the reason, such an investor panics and sells the portfolio. Such a habit of buying and selling at low prices may lead to overlooking a potential rise in prices after sell of securities. Robo-Advice systems are not guided by emotions. If markets rise or fall, the AlgoTrading algorithms should prevent making 'inadequate' choices and should help in maintaining a constant risk level. 


\section{Weaknesses of Robo-Advice}

The investment costs are not minimised and the aspect of low charges in comparison with traditional consulting companies deserves a word of criticism. Robo-Advice platforms are criticised for advertising their products as 'low-charge' or 'zero-charge' services, which may not necessarily be true. Such fees are often masked with lower returns from investors' portfolios or the fees are greatly increased after a certain period defined in company's strategy.

The conflict of interests is often a weak point of many systems. The FINRA [2016] report draws Robo-Advice clients' attention to the necessity of being aware that the systems may not entirely eliminate conflicts of interests present in financial consulting. Often, it is completely opposite. Robo-Advice systems maintain relations with interrelated brokers, accounting companies, trustees and other companies, to provide services of automated investments for their clients. Should they not use the possibility of intermediate charges, they would not generate any incomes. In particular, some Robo-Advice services reveal that they 'may feature interests or items in securities of the recommended clients', which indicates an additional conflict of interests, for example provision payments for such instruments [Fein 2015]. As a consequence, there are conflicts of interests at two conceptual levels: first, with relation to the interrelated brokers; second, with regard to selection of the recommended assets.

Poor evaluation of risk tolerance and lack of personalisation: an often criticism pertains to evaluation of Robo-Advice systems' risk assessment on the basis of the prepared questionnaires. The SEC \& FINRA [2015] report warns the investors that the questionnaires are filled in to define, which investment strategy is best suited for the investor. Often, it does not give consideration for individual goals and may be based on additional, incorrect assumptions, incomplete information or circumstance irrelevant for investors (e.g.: age, time perspective and individual targets). Moreover, Tertilt \& Scholz [2017] have recently published a research on usage of questionnaires for evaluation of risk levels. They discovered that among the researched Robo-Advice platforms from Germany, USA and UK, only $60 \%$ of the questions had influenced the risk categorization [Dorfleitner et al. 2017]. Aside to that, they identified Robo-Advice systems, which issue recommendations similar to that of human advisers.

When taking a closer look at the mechanisms of balancing, there are a lack of personalisation and (possibly) incorrect advices present. Summing up, it seems that due to the lack of personalisation in risk evaluation and balancing, Robo-Advice platforms, as of now, do not provide for the needs of investors with moderately complex demands. Concentration on some of the elements only (questions in a questionnaire) and lack of analysis for other elements of individual 
finances, makes it impossible to fully personalize the portfolio, as well as define the right risk.

No direct contact is one of the major and most important features of Robo-Advice. At one hand, this may be perceived as a benefit, as the charges are lower, and consulting services are offered to a larger group of clients. On the other hand, there is a question: is impersonal investment consulting something a client really wants [Jung et al. 2019]? An adviser in the field of personal finances (long-term relation) is a solution to a very delicate issue, namely confidentiality and secrecy of some data, maintaining due diligence, while a system may send you modification of a testament agreement via email just on the basis of the calculated probability of such a scenario [Cocca 2016]. This example serves as an illustration to the lack of personal relations with a financial adviser. More to that, the clients are left on their own when they try to assess whether the delivered investment strategies answer to their needs and goals [Fein 2015]. Robo-Advice is still only a system, a soulless machine, thus an unfulfilled fiduciary duty (due diligence in acting in the best interest of clients when providing financial advices) pertains to many clients. Robo-Advice systems do not provide general portfolio analyses, as they assess the investments independently (for each assets class) and do not elaborate general investment strategies on behalf of a client. Additionally, Fein [2015] claims that Robo-Advice, in a limited scope, makes consideration for individual client's conditions or other external factors, which may lead to catastrophic consequences, for example in sudden market scenarios. At the end, he states that only professionally trained advisers may unfailingly mange portfolios [Fein 2015].

\section{Opportunities and Possibilities of Robo-Advice}

The ubiquity of digital services, that is financial industry and assets management undergo constant demographic and technological changes. Thus, the behaviour of consumers changes as well. People are connected via smartphones, tablets, notebooks and other devices, everywhere and all the time. Today's digitalization of everyday life constitutes a good foundation for Robo-Advice to establish operation on a market dominated by conventional institutions dedicated to manage assets. Indeed, Gauthier et al. [2015] states that advices given by robots are clearly directed to a younger, tech-savvy generation. In his study, Cocca [2016] shows that $30 \%$ of respondents of a survey conducted in Europe may imagine using a purely automated investment adviser, whereas the percentage rises to $45 \%$ when excluding the population at the age of 60 or above, as they tend to stick to their habits.

Possibility of standardization and integration: except for the services, such as portfolio re-balancing and automatic consulting, the industry's offer of assets 
management is still much greater. For more complex services are being offered, which are difficult to be standardized and mass-adjusted by Robo-Advice systems, including, e.g. insurances, inheritance succession, pension, immovables, taxes. The complexity intensifies due to the fact that they are executed in local and trans-border and international scope, within the EU. Full integration and combination of financial, legal and tax matters on the international level is a very complex process. Nevertheless, the possibility of standardization and integration of more complex services is a key factor that draws more clients, who are currently relying on traditional personal advisers. As Cocca states [2016: 51], the established traditional advisers may have an advantage in this respect, as they feature decades of experiences in personal financial planning.

Target-based investments: a simple approach to assessment of clients' risk profiles with questionnaires and to employment of the modern theory of portfolio concept for optimization of a portfolio has been discussed earlier in the paper. In order to prospectively resolve such issues connected with the simplification - with the assumption that the market variability is a key condition for return - the philosophy of a target-oriented investment is a long-term goal of a consulting company, as it basically differs from the concept of optimization of average variance. In connection with the above, the investors and their individual values, investment targets, priorities, time perspective and risk profiles are in the focus [Sironi 2016]. As every man differs with the combination of pre-defined attributes, a much individualised model should be devised to reach a high level of customisation and optimally satisfy clients' needs.

A complement for traditional advisers is a Robo-Advice system, utilised as a basic work tool. With time, the number of technological solutions will rise. Today, Financial Advisers (in the field of personal financial planning) may use tools for analysis of insurances and banking products and recommend Robo-Advice platforms for investments to their clients. New technologies and solutions lure clients and thus the traditional consulting services - if properly supported by systems - are the key to the development of operations.

\section{Threats of Robo-Advice}

Competitive environment: the future threat for every Robo-Advice platform on the market is a high competitiveness that needs to be faced. This competitiveness is currently and in majority limited to national markets. But if the regulatory environment, investment practices and other barriers for entering foreign markets change, the international competitions will rise, and smaller players will have to face much larger companies from the U.S. What is more, independent Robo-Advice operators face an enormous challenge of the competition, that is Robo- 
-Advice platforms established by traditional consulting companies and financial institutions.

No users' acceptance: as already stressed, the changes in behaviour and growing relation with technology indicate that the Millennials are an attractive target group for Robo-Advice [Gauthier et al. 2015]. However, this does not have to mean that a large group of potential users really accepts Robot Advisers as a real opportunity in comparison to detail investments or personal adviser.

Research conducted by Ludden et al. [2015] indicate that $77 \%$ of respondent clients who manage their assets trust their financial advisers. What is more, $81 \%$ claims that face-to-face interaction is important. This means that personal consulting is still a highly demanded function of financial advisers. On top of that, the clients state that contemporary Robo-Advice offering does not fulfil the needs of investors operating in complex financial environment. This that Robo-Advice lacks trust, although it might be attributed to other reasons, like higher costs or laziness when it comes to changing investments. As a result, Robo-Advice operators start to introduce hybrid solutions, offering personal advisers, additionally to the system service. For example: Betterment has recently introduced a call centre manned with certified financial planners in order to monitor accounts and advise.

Possible threat posed by control authorities: recently, many institutions and individuals articulated, for a number of reasons, the growing fear for regulation of the consulting in the field of digital investments. For instance, Fein [2015] is worried with potential conflict of interests, lack of personal advice and reports fears for fiduciary duties. Moreover, Novick et al. [2016] provide for good situation overview, which institutions have lately been engaged with fears stemming from Robo-Advice regulations. FINRA [2016] and SEC \& FINRA [2015] indicate the existence of fears resulting from the supervision over algorithms, conflicts of interests, practices in terms of clients profiling and automatic balancing, showing that there is a need for advanced regulation of Robo-Advice. Baker and Dellaert [2017: 4] also see the need for presence of regulatory bodies, but represented by lawyers, economists and scientists who handle the personal financial planning and are already engaged in regulations of financial services, to best match the regulations. They mention also the need to regulate Robo-Advice due to a new scale of risk, as all investors use similar algorithms [Baker and Dellaert 2017].

The resent occurrences and growing fears with relation to digital investment consulting regulations constitute a potential threat to the Robo-Advice branch. If the regulations are tightened in the future, this may affect the profitability due to the rise of costs, when the rules are not observed.

Bear market and crisis: many investors are worried with the fact that the currently operating Robo-Advice suppliers have never experiences any crisis nor 
bear market. Among others, Fein [2015] claims that he is worried with how Robo-Advice operators will manage when the market slumps. Traff [2016], on the other hand, claims that robot advisers have this advantage - they practically do not make decisions based on emotions and thus they generate better results than detail investors or even the traditional financial advisers, who are individually biased, both emotionally and cognitively.

Nevertheless, the questions of how Robo-Advice operators will handle in the case of extreme market crashes, such as 2008 financial crisis, remains unanswered. So, it is not clear whether the trust to Robo-Advice is large enough, not to sell these systems pro-actively, even in the period of extreme market shifts. And maybe in extreme situations, a personal adviser will be perceived as a more trustworthy person.

Summarizing the considerations in Scheme 2, the Robo-Advice SWOT analysis is presented.

\begin{tabular}{ll}
\hline \multicolumn{1}{c}{ Helpful Positive Characteristics } & Harmful Negative Characteristics \\
\hline $\begin{array}{l}\text { Strengths } \\
\text { Lower fees and minimum investment }\end{array}$ & Weaknesses \\
Investment costs are not minimized \\
Tax-loss harvesting & Conflict of interests \\
Investment experience & Poor assessment of risk tolerance and \\
Portfolio construction by algorithms and & lack of personalization \\
automated rebalancing & No personal contact \\
Less emotional decision making & Unfulfilled fiduciary duty \\
Opportunities & Threats \\
Ubiquity of Digital Services & Competitive environment \\
Opportunity to standardize and integrate & No acceptance of users \\
Goal-based investing & Possible threat from regulators \\
Complement traditional advisors & Bearish market and crisis
\end{tabular}

Scheme 2. Overview of the key characteristics of the SWOT analysis of Robo-Advisory Source: Jung et al. 2017.

\section{CONCLUSIONS}

Behavioural changes stemming from a more intensive operation of electronic devices, may make Robo-Advice more attractive for investors from younger generations. Moreover, investments based on targets and individual target, values, 
time perspectives customization may be subsequent steps undertaken by Robo-Advice. Nevertheless, Robo-Advice platforms meet with scepticism, especially from the side of regulatory organs and with clients' reluctance and restricted trust. Thus, despite all of these promising prognoses, the industry faces threats. First, the environment becomes increasingly competitive. Second, it is not clear whether users will accept fully automatic investment tools without direct and personal contact, and personal financial planning in subsequent stages. And third, the threat may be posed by future regulations of this market. Therefore Robo-Advisors are not a threat to traditional financial advisors, but their complement, which makes the hybrid model connecting a physical advisor assisted by technological solutions (Robo-Advisors) most likely.

\section{BIBLIOGRAPHY}

Anderson T., 2017, More robo-advisors are adding a human touch to their services, https://www.cnbc.com/2017/01/31/more-robo-advisors-are-adding-that-human-touch.html [access 20.06.2019].

Arnott R.D., Berkin A.L., Ye J., 2000, How Well Have Taxable Investors Been Served in the 1980s and 1990s?, „The Journal of Portfolio Management”, vol. 4, pp. 84-93.

Baker T., Dellaert B., 2017, Regulating robo advice across the financial services industry, ERIM report series research in management in Erasmus Research Institute of Management.

Cocca T.D., 2016, Potential and Limitations of Virtual Advice in Wealth Management, „The Capco Institute Journal of Financial Transformation",vol. 44, pp. 45-57.

Dorfleitner G., Hornuf L., Schmitt M., Weber M., 2017, FinTech in Germany, Springer International Publishing, Cham.

European Securities and Markets Authority, 2007, MIFID and MIFIR.

Fein M.L., 2015, Robo-Advisors - A Closer Look, SSRN Working Paper 2658701 , http://ssrn.com/abstract_2658701 [access 8.06.2019].

FINRA, 2016, FINRA Reports on Effective Practices for Digital Investment Advice.

Gauthier V., Laknidhi V., Klein P., Gera R., 2015, Robo-Advisors: Capitalizing on a growing opportunity, Deloitte.

Jung D., Dorner V., Weinhardt C., Pusmaz H., 2017, Designing a Robo-Advisor for Risk-Averse, Low-Budget Investors, Electronic Markets, doi: 10.1007/s12525-017-0279-9.

Jung D., Dorner V., Glaser F., Morana S., 2018, Catchword Robo-Advisory - Digitalization and Automation of Financial Advisory, Business \& Information Systems Engineering, BISE, vol. 60, issue 1, doi: 10.1007/s12599-018-0521-9.

Jung D., Glaser F., Köpplin W., 2019, Robo-Advisory - Opportunities and Risks for the Future of Financial Advisory, [in:] V. Nissen, Advances in Consulting Research Recent Findings and Practical Cases, Springer.

Kocianski S., 2016, The Robo-Advising Report: Market forecasts, key growth drivers, and how automated asset management will change the advisory industry, Business Insider.

Lam J.W., 2016, Robo-Advisors: A Portfolio Management Perspective, Yale College.

Ludden C., Thompson K., Mohsin I., 2015, The Rise of Robo-Advice: Changing the Concept of Wealth Management, Accenture.

Markowitz H., 1952, Portfolio selection, „The Journal of Finance”, vol. 1, pp. 77-91. 
Nicoletti B., 2017, The Future of FinTech. Integrating Finance and Technology in Financial Services, Palgrave Studies in Financial Services Technology.

Novick B., Lu B., Fortin T., Hafizi S., Parkes M., Barry R., 2016, Digital Investment Advice: Robo Advisors Come Of Age, www.blackrock.com/corporate/literature/whitepaper/viewpointdigital-investment-advice-september-2016.pdf [access 13.03.2020].

Reher M., Sun C., 2016, Robo Advisers and Mutual Fund Stickiness, January, SSRN Electronic Journal DOI: $10.2139 / \mathrm{ssrn} .2872134$

Saad L., 2016, Robo-Advice Still a Novelty for U.S. Investors, Marketplace, July 27, https://news.gallup.com/poll/193997/robo-advice-novelty-investors.aspx [access 15.02.2020].

SEC, FINRA, 2015, Investor Alert: Automated Investment Tools, https://www.sec.gov/oiea/investor- alerts-bulletins/autolistingtoolshtm.html [access 6.06.2018].

Schapiro K., 2017, Backend Benchmarking - The Robo Report Q1 2017, https://theroboreport.com [access 6.06.2018].

Sironi P., 2016, FinTech innovation: From robo-advisors to goal based investing and gamification. The Wiley Finance Series: John Wiley \& Sons Ltd.

Tertilt M., Scholz P., 2017, To Advise, or Not to Advise - How Robo-Advisors Evaluate the risk Preferences of Private Investors , https://ssrn.com/abstract=2913178 [access 10.06.2020].

Traff J.D., 2016, The Future of the Wealth Management Industry: Evolution or Revolution?, MBA-Submission, Massachusetts Institute of Technology, https://dspace.mit.edu/handle/1721.1/104548 [access 5.06.2017].

Waliszewski K., 2020, Robo-doradztwo jako przyktad fin-tech-problem regulacji i funkcjonowania, „Przegląd Ustawodawstwa Gospodarczego”, nr 7/2020 (865), doi: 10.33226/01375490.2020.7.2.

Waliszewski K., Warchlewska A., 2020, Attitudes Towards Artificial Intligence in the Area of Personal Financial Planning: A Case Study of Selected Countries, „Entrepreneurship and Sustainability Issues", vol. 8, no. 2, pp. 399-420, DOI:10.9770/jesi.2020.8.2(24)

Wong M.M., 2015, Hungry Robo-Advisors Are Eyeing Wealth Management Assets: We Believe Wealth Management Moats Can Repel The Fiber-Clad Legion, Morningstar Equity Research, 31 March. 